\title{
Educação infantil no Brasil: reflexões sobre a supervisão e a gestão de recursos humanos ${ }^{1}$
}

Child education in Brazil: reflections on the supervision and human resource management

Educación infantil en Brasil: reflexiones sobre la gestión de supervisión y recursos humanos

\section{FABIANA SILVA FERNANDES MARIA MALTA CAMPOS}

\begin{abstract}
Resumo: $\mathrm{O}$ artigo reporta-se à pesquisa sobre gestão da educação infantil no Brasil, realizada em 2011 e 2012, em seis capitais. Apresenta parte da dimensão qualitativa do estudo, cujas fontes de informação foram as entrevistas realizadas nas Secretarias Municipais de Educação. Os dados referem-se ao trabalho de supervisão na educação infantil, aos recursos humanos que trabalham com as turmas de creches e pré-escolas e às formas de ingresso para o cargo de diretor. Constatou-se que: as atividades de supervisão estão vinculadas à formação continuada; existem planos de carreira diferenciados para professores de educação infantil, professores de outras etapas da educação básica e para auxiliares de turma. A indicação e a eleição são os mecanismos mais utilizados para a ocupação do cargo de diretor.
\end{abstract}

Palavras-chave: Educação Infantil, Gestão Educacional, Municípios

\begin{abstract}
The article refers to the research on management of early childhood education in Brazil, held in 2011 and 2012 in six capital cities. It shows part of the qualitative aspect of the study. The sources of information were the interviews conducted in the Municipal Secretariats of Education. The data relate to the supervision work in early childhood education, human resources working with daycare classes and preschools, and forms of admission to the post of director. The study found that the supervisory activities link to the continuing education. There are different career paths between preschool teachers, teachers on other stages of basic education and classroom assistants. The nomination and the election are the most commonly used mechanisms for filling the post of director.
\end{abstract}

Keywords: Early Childhood Education, Educational Management, Municipalities

Resumen: El texto se refiere a la investigación sobre la gestión de la educación de la primera infancia en Brasil, que tuvo lugar en 2011 y 2012 en seis ciudades. Muestra parte del aspecto cualitativo del estudio, cuyas fuentes de información fueron las entrevistas llevadas a cabo en los Departamentos 
Municipales de Educación. Los datos se refieren al trabajo de supervisión en la educación infantil, los recursos humanos que trabajan con las clases de jardines de infantes y preescolares y formas de admisión en el cargo de director. Se encontró que: las actividades de supervisión están vinculados a la educación continua; hay diferentes trayectorias profesionales entre maestros y profesores de otras etapas de la educación básica preescolar y entre los maestros de preescolar y asistentes de aula y la nominación y los mecanismos de elección son los más utilizados para la provisión del puesto de director.

Palabras clave: Educación de la Primera Infancia, Gestión de la Educación, Municipios.

O trabalho tem como propósito apresentar resultados de investigação sobre a gestão da educação infantil ${ }^{2}$, no plano da gestão municipal, que é a esfera de governo legalmente incumbida por ofertar essa etapa educacional, no Brasil.

A pesquisa foi realizada em seis capitais brasileiras, no ano de 2011, contemplando as dimensões de gestão das secretarias municipais de educação e das unidades escolares, de modo a caracterizar as políticas de gestão da educação infantil nas redes municipais de ensino e de identificar modelos de gestão aplicados nas unidades.

No âmbito da unidade, as principais questões cobertas pela investigação contemplam o perfil dos profissionais (diretor, coordenador pedagógico e professor), o seu cotidiano de trabalho (natureza das tarefas, trabalho pedagógico, relações com famílias, equipe e comunidade), o seu modelo de gestão e as suas opiniões e reflexões acerca da educação infantil.

Junto às secretarias municipais de educação, os seguintes aspectos foram pesquisados, cada um deles desdobrado em diversos itens: organização dos sistemas municipais de educação; perfil da rede municipal; supervisão pedagógica; recursos humanos, financeiros e materiais; formação continuada; orientações curriculares; integração com o ensino fundamental e integração com demais setores sociais.

Esse trabalho detém-se na dimensão da gestão municipal, apresentando resultados da investigação sobre os seguintes aspectos: supervisão pedagógica e recursos humanos.

\footnotetext{
2 A pesquisa, intitulada "A gestão da educação infantil no Brasil" resulta de uma parceria estabelecida entre a Fundação Victor Civita e a Fundação Carlos Chagas. Contou com a participação de equipes locais, formadas por pesquisadores vinculados às universidades federais situadas nas capitais selecionadas para o estudo.A equipe da Fundação Carlos Chagas foi a seguinte: Maria Malta Campos (coordenadora), Yara Espósito, Nelson Gimenes, Eliana Bhering, Beatriz Abuchaim, Fabiana Silva Fernandes e Bruna Ribeiro.
} 


\section{ALGUNS APONTAMENTOS SOBRE A LITERATURA}

As reformas educacionais introduzidas em diversos países nas últimas décadas deram prioridade à introdução de inovações na gestão das redes de ensino e das unidades, reforçando processos como a descentralização, a garantia de maior autonomia para as unidades e a avaliação de sistemas. A bibliografia especializada sobre esse tema é vasta, tanto no exterior como em nosso país.

No entanto, muito pouco tem sido pesquisado sobre a gestão da educação infantil no país (TOMÉ, 2011; CAMPOS et al, 2012). Essa lacuna é especialmente grave devido ao fato de que a gestão de creches e pré-escolas apresenta especificidades importantes, quando comparada à gestão de escolas que atendem crianças maiores de 6 anos de idade.

Ao examinar-se a literatura sobre a gestão em educação infantil verificase que as publicações são relativamente escassas, quando comparadas à literatura sobre a gestão da educação em geral; focalizadas nas etapas posteriores da educação; baseadas, na maioria das vezes, em estudos de caso, reflexões sobre experiências localizadas, com pouca abrangência; mantendo uma interlocução limitada com as discussões mais gerais que vêm acompanhando a introdução das reformas educacionais, ocorridas nas duas últimas décadas, que impactam de perto a gestão dos sistemas e unidades de ensino.

Uma possível razão para explicar essas características da bibliografia disponível no país é o fato de a educação infantil, especialmente a creche, ter sido integrada recentemente ao sistema educacional. Ainda que a Constituição Federal, em 1988 e, posteriormente, a pela Lei de Diretrizes e Bases da Educação Nacional - LDB, de 1996, já qualificassem a educação infantil como primeira etapa da educação básica, junto com o ensino fundamental e o médio, a transição do atendimento, que estava sob a responsabilidade da área de assistência social, para o setor da educação, foi lenta, envolvendo um esforço maior do Ministério da Educação (MEC) e do Ministério do Desenvolvimento Social (MDS), em 2006, para que esse movimento se concretizasse.

Muito pouco tem sido pesquisado e publicado sobre a gestão da educação infantil. Dentre mais de 700 fontes localizadas na Base de Dados "Gestão Escolar”, disponível na página da Fundação Carlos Chagas, entre 2001 e 2008, foram localizados apenas seis artigos, quatro teses e catorze dissertações a partir do descritor "gestão da educação infantil". Dentre 63 títulos de livros levantados para serem incluídos nessa base, nenhum trata especificamente da gestão da educação infantil. Consultando o banco de Teses da Capes, no período de 2009 e 2010, foram encontradas duas teses e quatro dissertações sobre o tema.

Acrescenta-se à falta de um estudo mais aprofundado sobre a gestão 
da educação infantil, a difusão de práticas e procedimentos já consolidados nos sistemas educacionais. Como recém-chegada ao setor educacional, a educação infantil acaba por ser aquela etapa que precisa ajustar-se a modelos de gestão desenhados para outros níveis educacionais, modelos esses que já contam com uma história e com uma legitimidade que reforçam sua imposição às instituições de educação da criança pequena (CÔCO, 2009). Assim, é a creche e a préescola que precisam se adaptar às estruturas e mecanismos já consagrados de organização e gestão dos sistemas e não o inverso. Peter Moss (2011) utiliza uma expressão interessante para se referir a esse tipo de processo: a "colonização" da educação infantil pelas etapas posteriores de educação, processo este observado em procedimentos organizacionais e na gestão da educação infantil, na pesquisa realizada.

\section{SUPERVISÃO DA EDUCAÇÃO INFANTIL MUNICIPAL}

As capitais brasileiras que participaram dessa investigação (denominadas A, B, C, D, E e F para garantir o anonimato) localizam-se em quatro das cinco regiões do país, estando excluída a região norte. Para o estudo da educação infantil desses municípios, no âmbito da pesquisa, um dos instrumentos de coleta de dados utilizado foi a entrevista dirigida com as equipes responsáveis pela educação infantil nos municípios, com o propósito de obter informações sobre a organização e a gestão municipais de educação infantil, entre eles o trabalho de supervisão e os recursos humanos empregados para o trabalho com as turmas de crianças atendidas em creches e pré-escolas. As visitas às secretarias municipais foram realizadas nos meses de outubro a dezembro de 2011, e as entrevistas foram acompanhadas pelas equipes locais de pesquisa.

Mediante as informações obtidas, verificou-se que o trabalho de supervisão na rede direta, em três municípios, está estreitamente articulado ao trabalho de formação continuada, mediante a eleição de temas de formação, sobre os quais se realizam os encontros entre os supervisores e os profissionais das instituições de educação infantil.

Em dois dos municípios, a supervisão não é um cargo previsto na rede municipal de ensino e não há o planejamento de atividades sistemáticas de supervisão pedagógica.

No caso da supervisão das instituições conveniadas, observou-se que é diferenciada e se restringe mais ao papel tradicional de verificar os aspectos organizacionais e funcionais da instituição. No município D, por exemplo, a equipe do departamento de educação infantil faz o acompanhamento direto das entidades conveniadas e seu programa de supervisão é mais restrito aos 
procedimentos administrativos e financeiros, diferentemente do que ocorre na rede direta, em que há toda uma articulação entre as atividades de formação e acompanhamento do processo pedagógico pelos supervisores.

Já no município $C$, as orientações de supervisão da secretaria de educação são as mesmas para entidades conveniadas e instituições da rede direta e são circunscritas à supervisão pedagógica das instituições, pois o acompanhamento administrativo das entidades conveniadas fica à cargo de outro setor.

Notou-se que, com exceção dos municípios D e A, as equipes de supervisão respondem diretamente à secretaria de educação, enquanto no município $\mathrm{D}$, há uma estrutura de supervisão bastante hierarquizada: as supervisoras dos núcleos regionais são subordinadas diretamente ao departamento de educação infantil e a equipe de pedagogas de educação infantil é subordinada às supervisoras dos núcleos regionais, responsáveis por cobrir uma média de oito a dez instituições.

O município C não possui o cargo de supervisor previsto oficialmente. A secretaria seleciona informalmente professores da rede de educação infantil, que são chamados de acompanhantes, para realizar o monitoramento das instituições:

Dentro dessa gerência de educação infantil tem a equipe de acompanhamento de educação infantil, que é específica, que é selecionada, tem entrevista... Antes saía publicado no diário oficial para a gente compor essas equipes. Depois, a gente viu que estava muito difícil essa estratégia e começou a fazer de uma forma diferenciada; o próprio acompanhante de educação infantil, que vai às instituições e percebe um educador ou professor com perfil para estar nessa equipe, ele já indica para a gente: "olha, um professor, um educador da instituição tal desenvolve um trabalho bacana, tem uma concepção de gestão, dá para chamar para entrevista”. Daí, a gente pede para trazer um memorial, faz uma entrevista e se a gente avalia que é pertinente a sua experiência, o seu perfil, a gente traz para cá. E aí a gente faz uma formação inicial, (...) e a gente faz também uma avaliação processual e uma no final do ano, definindo se a equipe permanece ou não e por quê. (...) ela ganha a pasta como essa aqui, o be a ba da acompanhante, que tem todas as normas, todas as leis.

Outro aspecto importante é o planejamento do trabalho de supervisão. No município D, a supervisão é planejada anualmente, com a previsão do cronograma de visitas e das pautas de reuniões das diferentes equipes que fazem o trabalho. No município C, são realizadas semanalmente reuniões na secretaria para prever as ações de supervisão, que seguem a mesma orientação para as instituições públicas e conveniadas. Já no município F, a equipe de educação infantil elabora um protocolo de atendimento, com uma pauta pré-determinada para a supervisão nas unidades.

No município B, o setor de educação infantil avalia as demandas feitas durante o ano anterior e faz um planejamento das ações e dos focos que vão ser adotados em cada ano. No entanto, diferentemente dos municípios anteriores, não 
há uma escala de visitas às unidades, planejada com antecedência, na medida em que as unidades podem solicitar a visita das equipes quando sentem necessidade. Estas se organizam para não haver desencontros ou paralelismo de ações, por meio do planejamento das visitas agendadas e do registro escrito dos principais problemas observados pela supervisão em cada centro de educação infantil, que devem ser objeto de atuação da equipe no ano seguinte.

Em relação à realização da supervisão, o departamento de educação infantil do município $\mathrm{D}$, anualmente, com base nas experiências e demandas da rede, elege temas de formação, sobre o qual se realizam as atividades de supervisão. A supervisão tem uma pauta geral, que diz respeito ao conteúdo da formação e uma pauta específica, sobre questões de cada unidade ou núcleo. As supervisoras dos núcleos regionais reúnem-se com a equipe central, para definirem as pautas de formação e supervisão das pedagogas que, por sua vez, trabalham com os coordenadores pedagógicos das unidades, responsáveis por formar e acompanhar o trabalho dos professores e educadores. À formação é vinculado um plano de ação, que os professores devem elaborar e implementar, mediante o acompanhamento do coordenador responsável pela unidade, pois a equipe do departamento de educação infantil entende que a supervisão é uma continuidade da formação e sua finalidade é verificar como os professores estão atuando, tendo por base a formação implementada.

No município E, a secretaria também articulou a supervisão à formação dos profissionais, particularmente em relação à elaboração do projeto pedagógico das instituições, que é um tema constante de formação e são as supervisoras que coordenam e encaminham diretamente esse processo de elaboração e avaliação das propostas elaboradas pelas instituições. As orientações curriculares também subsidiam o trabalho de supervisão. Para a educação infantil, há orientações para a prática educativa pedagógica sobre os seguintes aspectos: o cotidiano e a rotina de trabalho na instituição e o desenvolvimento do trabalho pedagógico e metodológico para as crianças de 0 a 6 anos. A secretaria também investe em diretrizes curriculares e a formação dos profissionais é pautada nos documentos elaborados pelo setor. Tal como no município D, os documentos orientadores são produzidos a partir das experiências e das dificuldades levantadas na rede.

No caso do município F, na supervisão é feita a leitura de textos dentro da temática eleita pela equipe da educação infantil da secretaria; também se utiliza o referencial municipal para a pré-escola (o documento similar para a creche se encontrava em processo de elaboração, quando da realização da entrevista). As supervisões, tal como em B, são registradas, de modo a compartilhar as informações obtidas com toda a equipe de supervisão para a construção de pautas futuras e para subsidiar as ações da secretaria. 
O planejamento pedagógico, no município $\mathrm{F}$, é feito a partir de alguns elementos acordados entre a equipe e os profissionais nas unidades. Não há um modelo único, podendo assim, a unidade, ter liberdade para construir o seu próprio, desde que considere os elementos acima mencionados, como por exemplo, a avaliação das crianças, a qual pode ser feita em formato de relatório escrito ou planilha. Para as crianças de cinco anos, depois de discussão com as unidades, as equipes da secretaria e das pré-escolas elaboraram um instrumento que toda a rede deve usar para acompanhar a criança.

No município C, os profissionais que exercem a supervisão são profissionais recrutados pela gerência de educação infantil entre aqueles que trabalham nas unidades, para realizar as visitas às unidades municipais e conveniadas. Os profissionais, denominados acompanhantes, supervisionam três unidades se trabalham em meio período e seis se trabalham em período integral. Nas creches conveniadas, além da supervisão pedagógica é feita a verificação da frequência das crianças, segundo o plano de trabalho da instituição.As supervisões são documentadas; há um relatório por visita, para o caso de fiscalização de situações que precisem ser corrigidas. São produzidas planilhas contendo a relação das ações desenvolvidas e relatório da avaliação das equipes regionais.

No município A, não há o cargo de supervisor pedagógico. As visitas são realizadas pelas próprias técnicas do departamento, que se encaminham às instituições quanto existe a solicitação da equipe gestora. De acordo com informações da secretaria municipal, as técnicas procuram orientar as coordenadoras pedagógicas para fazer a supervisão e a orientação pedagógica. No entanto, não existe um processo organizado de supervisão, um cronograma/ escala de visitas sistemática às unidades. Conforme depoimento, nessa secretaria:

As coordenadoras pedagógicas são orientadas a realizarem este trabalho. Oferecemos orientações sobre como os professores devem realizar a avaliação na educação infantil. Quando as escolas necessitam realizamos as visitas, a demanda parte da escola, não há visitas sistemáticas. (...) Não existe supervisor de educação aqui..., não tem. Já temos coordenadores, que ficam nas escolas. Acho que a maioria das escolas de educação infantil já tem coordenadores pedagógicos, que são professores da rede.

As informações sobre a supervisão pedagógica dos municípios estão resumidas no quadro 1 , a seguir. 


\section{Quadro 1}

Informações sobre a supervisão pedagógica nos municípios

\begin{tabular}{|c|c|c|c|c|c|c|c|}
\hline Municípios & $\begin{array}{c}\text { Cargo } \\
\text { previsto e } \\
\text { regulamentado }\end{array}$ & $\begin{array}{c}\text { Estrutura } \\
\text { organizacional } \\
\text { da supervisão } \\
\text { pedagógica }\end{array}$ & $\begin{array}{c}\text { Articulação } \\
\text { da } \\
\text { supervisão/ } \\
\text { formação } \\
\text { da rede }\end{array}$ & $\begin{array}{c}\text { Subsidia } \\
\text { as ações } \\
\text { da SME na } \\
\text { gestão da } \\
\text { rede }\end{array}$ & $\begin{array}{c}\text { Planejada } \\
\text { com } \\
\text { escala } \\
\text { de visitas } \\
\text { previstas }\end{array}$ & $\begin{array}{c}\text { Supervisão } \\
\text { subsidiada } \\
\text { por } \\
\text { documentos } \\
\text { orientadores }\end{array}$ & $\begin{array}{c}\text { Produção } \\
\text { de registros } \\
\text { sistematizados }\end{array}$ \\
\hline A & não & - & - & - & - & - & - \\
\hline B & $\operatorname{sim}$ & horizontal & não & Sim & não & $\operatorname{sim}$ & sim \\
\hline C & não & - & não & Não & $\operatorname{sim}$ & $\operatorname{sim}$ & sim \\
\hline D & $\operatorname{sim}$ & hierárquica & $\operatorname{sim}$ & Sim & $\operatorname{sim}$ & $\operatorname{sim}$ & s/ inform. \\
\hline E & $\operatorname{sim}$ & horizontal & $\operatorname{sim}$ & $\operatorname{Sim}$ & $\operatorname{sim}$ & $\operatorname{sim}$ & sim \\
\hline F & $\operatorname{sim}$ & horizontal & $\operatorname{sim}$ & $\operatorname{Sim}$ & $\operatorname{sim}$ & $\operatorname{sim}$ & sim \\
\hline
\end{tabular}

Com relação à rede conveniada, as secretarias que desenvolvem a supervisão articulada com a formação docente e possuem diretrizes e orientações curriculares para a rede, como os municípios D, E e F, afirmam disponibilizar os documentos orientadores da rede para as instituições, mas não ficou claro se há um investimento sistemático de esforços no sentido de promover a formação dos profissionais das conveniadas e verificar se as diretrizes são utilizadas, embora as secretarias afirmem haver planejamento da formação na reunião pedagógica para os profissionais das conveniadas. No entanto, não foi possível verificar em que condições esses planejamentos são realizados e o grau de intervenção da secretaria nesse processo. No depoimento de um membro da equipe do município $\mathrm{D}$, ficou claro que as questões pedagógicas, a formação dos profissionais e mesmo a alimentação são assuntos mais delicados e difíceis de serem supervisionados ou mesmo modificados:

A pauta [que] se dá é meramente organizacional, organização da matrícula, organização de secretaria, de documentos, do material que a secretaria manda... Esse material elas dizem muitas vezes que não chegou e guardaram no almoxarifado, você tem que trabalhar a questão, por isso a dificuldade que está no RH, do profissional que está ali contratado. Tem uma pauta de formação também, então a supervisão fica uma média de quatro, três horas ali; vai depender do profissional. Então, tem uma pauta que é de formação (...), e tem uma pauta de organização. Não vamos entrar na cozinha e dizer o que tem que ser feito lá, isso compete à vigilância, mas ao observar você tem que fazer uma interferência.

\section{RECURSOS HUMANOS: PLANOS DE CARREIRA E VALORIZAÇÃO DO MAGISTÉRIO}

Com relação aos recursos humanos das unidades de educação infantil, 
foram buscadas informações sobre o quadro de funcionários, particularmente dos profissionais que atuam diretamente com as crianças, de modo a verificar alguns aspectos: condição de trabalho, plano de carreira e processo seletivo.

Os profissionais que lidam diretamente com as crianças, particularmente nas creches, na maioria dos municípios, são os professores e os auxiliares, cuja nomenclatura varia de um local para o outro. A seleção desses profissionais ocorre por concurso público, mas, percebeu-se uma grande diferença entre as categorias funcionais em termos de formação e plano de carreira: os professores devem ter o ensino superior; se não o têm, os municípios têm desenvolvido estratégias de formação inicial. Quanto aos auxiliares, a eles é exigido o ensino médio, na modalidade normal. Além disso, há planos de carreiras distintos para esses profissionais e, geralmente, o plano de carreira do professor é mais atrativo, os níveis salariais são maiores e as possibilidades de progressão na carreira são mais amplas.

No município D, as explicações para a existência de planos de carreira distintos para professores e educadores (auxiliares) é o fato de a carreira de educador ser antiga, herança do período em que as instituições eram vinculadas à secretaria de assistência social. No entanto, mesmo depois da LDB, a prefeitura ainda fez um concurso para educador em que a formação mínima exigida foi a de nível médio. Verificou-se, na entrevista realizada no município, que essa não é mais a política da secretaria, que se tem esforçado para mudar esse quadro, exigindo que os educadores tenham a formação mínima em ensino superior para ingresso na profissão, pois, como afirmado na entrevista, a carreira com nível médio não mais se sustenta: os professores estão avançando e buscando qualificar-se cada vez mais em cursos de pós-graduação lato sensu. Isso tem gerado demanda por melhoria salarial e por um plano de carreira que contemple a ascensão profissional de acordo com a formação. No município, a carreira de educador foi reestruturada após discussões com o sindicato, em dezembro de 2006, assim como os serviços de atendimento social do município, que tiveram suas áreas de atividades redefinidas, juntamente com a educação infantil e os serviços de creche. No entanto, as carreiras ainda são distintas e a formação mínima exigida, quando da realização da entrevista, ainda era o magistério, embora, houvesse a intenção de modificá-la, Essa questão estava sendo discutida na Conferência Municipal, que ocorria por ocasião da entrevista, e a tendência era exigir a formação em nível superior para o ingresso na rede, a constituir-se em meta para os próximos dez anos.

Em direção oposta, situa-se o município C, que acentua as diferenças entre as carreiras de professora e de educadora infantil, cargo criado juntamente com os primeiros centros de educação infantil municipais: 
Atualmente, estão em exercício, na docência da educação infantil pública profissionais com duas carreiras distintas. As professoras, com formação superior em pedagogia, e a Educadora Infantil com formação em magistério nível médio. Esclarecemos que Educadora Infantil é a profissional específica para esta etapa da educação básica e as professoras que ainda atuam nas unidades são as que já se encontravam nessa situação e assim que aposentarem serão substituídas por Educadora Infantil. Muitas educadoras possuem curso superior e até pósgraduação, porém tal formação não as transforma em professoras, pois possuem carreira própria e são remuneradas como tal.

O cargo de Educador Infantil foi criado em 2003, exigindo do profissional a habilitação mínima em curso de nível médio, modalidade normal e carga horária diária de quatro horas e meia. Pinto (2009), aponta as contradições desse modelo de carreira e afirma que diferença salarial entre professoras e educadoras cria grande tensão no sistema, pois as educadoras recebem por volta de $60 \%$ do salário das professoras, ainda mais considerando-se que um número expressivo de educadoras possui formação superior, ainda que isso não seja exigência para o cargo.

O município B também estabelece planos de carreira distintos para professores e auxiliares, não sendo estes incluídos no quadro de magistério nem contando com tempo remunerado para planejamento, como explica a equipe a respeito dos horários de planejamento individual e coletivo previstos para cada tipo de profissional:

$\mathrm{Na}$ educação infantil, cinco tempos de cinqüenta minutos mais cinco tempos de trinta minutos diário coletivo no final de cada turno. Semanais, por professor, individual. E dentro da semana, ele tem também mais cinco tempos de trinta minutos a cada final de turno, que é coletivo. (O individual) geralmente é na escola. Na educação infantil é na escola. Isso só vale para o professor. Isso para uma jornada de vinte e cinco horas semanais. $\mathrm{O}$ professor de quarenta horas tem oito horas de planejamento. O professor de musica, arte, educação física tem oportunidade de ficar quarenta horas, que é o concurso que ele fez e aí ele tem oito horas de planejamento. (...) De acordo até mesmo com a organização da escola, eles [auxiliares] podem se organizar com esses tempos junto com a gestão. A gente tem algumas experiências em algumas unidades que conseguem se reorganizar e ter essa conversa com os assistentes, mas como eles são do quadro geral, eles não estão configurados como magistério, portanto um terço do planejamento eles não têm formalizado. Nós temos na atribuição deles, nas discussões de plano de ação, projeto político pedagógico, que eles estejam junto dessa discussão nesse tempo de planejamento.

No município $\mathrm{F}$, os planos de carreira também são diferenciados e se observa a seguinte situação: na pré-escola, há 100\% de profissionais com nível superior; no maternal $70 \%$ e no berçário, 50\%. Há também recreadores e 
educadores com nível médio, estes provenientes da secretaria de assistência social. Conforme informações obtidas na entrevista, a meta é sempre fazer concurso para professores com nível superior, tal como ocorreu em 2008, quando o concurso para professor tinha como exigência a formação mínima em nível superior.

Um aspecto importante a ser considerado no município $F$ é que o Plano Municipal de Educação está em processo de elaboração; os sindicatos e os profissionais da rede estão reivindicando novo enquadramento para todos os profissionais da educação infantil, em um plano de carreira integrado. Parece que isso tem gerado um movimento dos profissionais, desde os auxiliares até secretários de escola, em busca de melhora de seus níveis de escolaridade, ainda que não tenham a garantia de que seus planos de carreira os beneficiarão por essa formação. No entanto, há incentivos para que continuem aperfeiçoando sua formação.

No município E, cabe destacar a presença do auxiliar de ensino, enquadrado no magistério, e o auxiliar de sala, que não faz parte do quadro docente. Além disso, são previstos concursos para a contratação de professores substitutos, em caráter temporário. Uma informação importante é que, nas normas para contratação de professores em caráter temporário, é permitido o ingresso de professores com formação em ensino médio, tanto para a educação infantil quanto para o ensino fundamental, na falta de professor habilitado com graduação. Também é prevista em lei a contratação de auxiliar de sala por tempo determinado para as unidades educativas da rede municipal de ensino. Acredita-se que a contratação desses profissionais em caráter temporário seja uma estratégia para contornar as ausências de funcionários.

Em relação ao horário de trabalho, no município D, o professor tem assegurada em lei em sua carga horária semanal oito horas fora de sala de aula, para estudo e planejamento e trinta e duas horas em sala de aula com as crianças. Já os educadores não recebem por horas de estudo e planejamento. No município C, os professores recebem cerca de 1.500 reais mensais para uma jornada de 25 horas e os assistentes, para o quais se requer o curso de magistério, recebem 930 reais para 30 horas semanais. Os professores têm horário previsto para planejamento na jornada, mas os assistentes não, por não serem considerados do quadro do magistério.

No município E, também há diferenças, quanto à hora de planejamento remunerada, entre os professores de educação infantil e primeiros anos do fundamental, os de educação física e aqueles que atuam no segundo segmento do ensino fundamental. Enquanto os docentes de $5^{a}$ a $8^{a}$ série e educação física têm $30 \%$ de horas atividade em tempo, os professores de 1a a 4a série e educação infantil recebem em pecúlio; se seu contrato é de 40 horas, devem trabalhar 
oito horas por dia em sala e as reuniões e planejamento deverão acontecer fora do horário de trabalho. Esse fator tem gerado algumas dificuldades em relação aos programas de formação continuada na rede, os quais, de acordo com as informações da secretaria, parecem ter diminuído um pouco, pois as condições não favorecem a operacionalização desses cursos.

No município A, apenas os professores possuem plano de carreira, ainda que os professores de educação infantil, na grande maioria, não tenham a formação mínima exigida pela LDB. Quanto aos auxiliares, a situação é ainda mais precária.

No quadro 2, são apresentadas informações resumidas sobre os profissionais das unidades diretas:

\section{Quadro 2}

Profissionais do quadro do magistério da rede direta dos municípios

\begin{tabular}{|c|c|c|c|c|c|}
\hline Municípios & $\begin{array}{c}\text { Profissionais } \\
\text { que } \\
\text { trabalham } \\
\text { com as } \\
\text { crianças }\end{array}$ & $\begin{array}{l}\text { Plano de } \\
\text { carreira }\end{array}$ & $\begin{array}{c}\text { Pertencem } \\
\text { ao quadro } \\
\text { do } \\
\text { magistério }\end{array}$ & $\begin{array}{l}\text { Formação } \\
\text { mínima }\end{array}$ & $\begin{array}{c}\text { Horas de } \\
\text { planejamento }\end{array}$ \\
\hline \multirow[t]{2}{*}{ A } & Professor & não & $\begin{array}{c}\text { s/ } \\
\text { informação }\end{array}$ & $\begin{array}{l}\text { Ensino } \\
\text { superior }\end{array}$ & não \\
\hline & Auxiliar & não & $\begin{array}{c}\text { s/ } \\
\text { informação }\end{array}$ & $\begin{array}{c}\text { s/ } \\
\text { informação }\end{array}$ & não \\
\hline \multirow[t]{2}{*}{ B } & Professor & $\operatorname{sim}$ & $\operatorname{sim}$ & $\begin{array}{l}\text { Ensino } \\
\text { superior }\end{array}$ & $\operatorname{sim}$ \\
\hline & Auxiliar & $\operatorname{sim}$ & não & $\begin{array}{l}\text { Ensino } \\
\text { médio }\end{array}$ & não \\
\hline \multirow[t]{2}{*}{ C } & Professor & $\operatorname{sim}$ & $\operatorname{sim}$ & $\begin{array}{l}\text { Ensino } \\
\text { superior }\end{array}$ & $\operatorname{sim}$ \\
\hline & Auxiliar & $\operatorname{sim}$ & não & $\begin{array}{l}\text { Ensino } \\
\text { médio }\end{array}$ & não \\
\hline \multirow[t]{2}{*}{ D } & Professor & $\operatorname{sim}$ & $\operatorname{sim}$ & $\begin{array}{l}\text { Ensino } \\
\text { superior }\end{array}$ & $\operatorname{sim}$ \\
\hline & Educador & $\operatorname{sim}$ & $\operatorname{sim}$ & $\begin{array}{l}\text { Ensino } \\
\text { médio }\end{array}$ & não \\
\hline \multirow[t]{2}{*}{ E } & Professor & $\operatorname{sim}$ & $\operatorname{sim}$ & $\begin{array}{l}\text { Ensino } \\
\text { médio ou } \\
\text { superior }\end{array}$ & não \\
\hline & $\begin{array}{l}\text { Auxiliar de } \\
\text { ensino }\end{array}$ & $\operatorname{sim}$ & não & $\begin{array}{l}\text { Ensino } \\
\text { médio ou } \\
\text { superior }\end{array}$ & não \\
\hline \multirow[t]{2}{*}{$F$} & Professor & $\operatorname{sim}$ & $\operatorname{sim}$ & $\begin{array}{l}\text { Ensino } \\
\text { superior }\end{array}$ & $\operatorname{sim}$ \\
\hline & $\begin{array}{l}\text { Auxiliar e } \\
\text { recreadores }\end{array}$ & $\operatorname{sim}$ & não & $\begin{array}{l}\text { Ensino } \\
\text { médio }\end{array}$ & não \\
\hline
\end{tabular}

Nas instituições da rede conveniada, a situação do professor é ainda mais 
complicada: no município $\mathrm{D}$, por exemplo, o desejável é que o professor tenha nível superior e o auxiliar de professor, magistério ou que esteja cursando o nível superior. No entanto, são encontradas situações em que o atendente de educação infantil, que não pode assumir o exercício do magistério, está na sala de aula. Apesar do controle do sindicato, essas situações ocorrem.

Já no município E, a situação trabalhista dos profissionais nas unidades conveniadas, além dos professores cedidos pela rede, tem que se enquadrar nas normas de funcionamento das unidades de educação infantil. Note-se que a rede conveniada recebe professores do quadro do magistério público municipal. Contudo, enquanto os professores substitutos cedidos pela secretaria para as instituições conveniadas têm formação em licenciatura em Pedagogia, definido em edital, dos profissionais contratados pela entidade é admitida a formação mínima de magistério.

No município C, o valor do convênio foi ajustado com base nos salários e encargos sociais que deveriam estar sendo pagos para o quadro de pessoal empregado (coordenador administrativo, coordenador pedagógico, professores e funcionários operacionais), além dos gastos com água, luz, telefone etc. Porém, não há como a secretaria exigir da entidade que siga exatamente esse padrão no seu quadro de pessoal, tendo sido relatadas dificuldades, em relação a esse quesito, na gestão das unidades conveniadas.

A dificuldade de as secretarias garantirem que as entidades conveniadas sigam determinado padrão estabelecido, seja no que se refere à formação inicial dos profissionais da educação, seja às questões de ordem pedagógica ou, mesmo, às ligadas aos cuidados com a alimentação e a higiene, foi registrada em quase todos os itens do roteiro de entrevistas. Esse é aspecto importante na gestão municipal da educação infantil, que merece aprofundamento maior em outras pesquisas.

\section{FORMAS DE INGRESSO NO CARGO DE DIRETOR DAS INSTITUIÇÕES DE EDUCAÇÃO INFANTIL}

Para o ingresso no cargo de diretor das instituições de educação infantil, os procedimentos utilizados pelos municípios são indicação e eleição. Em nenhum dos municípios pesquisados é adotado o concurso público para diretor de unidade de educação infantil.

No município D, por exemplo, onde há eleições a cada três anos para a direção das escolas de ensino fundamental, na educação infantil, a direção da instituição, que é função gratificada, é exercida por professores ou educadores indicados. A equipe de educação infantil não está muito satisfeita com esse 
tipo provimento do cargo, pois existem pressões políticas para a indicação de determinadas pessoas, ainda que as técnicas afirmem que todas as contratações devem passar pelo departamento de educação infantil e que esse procedimento costuma coibir práticas clientelistas. Contudo, em depoimento, a diretora do departamento afirmou que a equipe está mobilizando-se para pensar em outras formas de provimento do cargo, que garantam a transparência e a democracia, mas ela tem dúvidas sobre ser a eleição o melhor procedimento:

\begin{abstract}
O que me preocupa é o seguinte: de que forma que a gente pode pensar num jeito mais democrático, mais transparente? Embora a gente faça com a maior transparência esse trabalho, mas que seja mais transparente aos olhos de todos. Mas que não seja um sistema tão desgastante como, eu acho, é o do ensino fundamental hoje, que tem eleição: brigam, é aquela briga de poder... Eu acho que isso é uma coisa que não dá para você ter dentro de um espaço com crianças tão pequenas. Então, essa é a nossa grande preocupação, minha grande preocupação, um tempo longo, daí troca, a diretora vira vice, a vice vira diretora, acaba ficando aquela coisa, sabe. Então assim, tem o concurso (em São Paulo é concurso), tem lugares que tem prova e eleição. Eu, nesse aspecto, não tenho uma opinião formada. O que eu penso é que esse modelo que a gente usa hoje e tem usado nesses últimos anos, é um modelo que já deu conta, não é? Agora (...) a gente precisa pensar numa forma mais efetiva, uma forma que não gere tantos problemas como a gente vê na escola. Então, eu olho para a escola e não gosto do que vejo e olho para nós e também não gosto do que vejo, não é a situação ideal, sabe.
\end{abstract}

Verifica-se, nesse depoimento, receio em relação ao sistema de eleição, pois, a experiência do ensino fundamental tem mostrado que o processo é desgastante, provocando desentendimentos e disputas pelo poder. Além disso, a mudança constante da equipe gestora parece gerar instabilidade, com reflexos no trabalho pedagógico das escolas de ensino fundamental. Nesse sentido, a diretora do departamento não compreende a eleição de diretores como o melhor mecanismo para o provimento do cargo de gestor escolar. Esse é um aspecto que merece ser aprofundado em estudos posteriores, uma vez que a eleição para diretores escolares tem sido apontada como mecanismo de gestão democrática.

No município B, os diretores são eleitos. Quem organiza as eleições é a gerência de gestão democrática, a qual se ocupa também dos conselhos de escola, que são as unidades executoras das instituições e que recebem os recursos descentralizados para as unidades de educação infantil e de ensino fundamental. A última eleição estava em andamento durante a visita dos pesquisadores da FCC a esse município. Posteriormente, o site da secretaria anunciou a seção solene de posse dos eleitos, com a presença do prefeito e autoridades municipais, revelando o caráter público de que se reveste esse processo naquele município.

$\mathrm{Na}$ rede municipal F, os diretores dos centros de educação infantil são indicados pela secretaria de assistência social e a secretaria de educação não opina 
nesse processo. Há informação de que a maioria dos diretores tem formação em pedagogia ou estão concluindo esse curso. No entanto, a gestão pedagógica e a inspeção das unidades são realizadas pela secretaria de educação; segundo a secretária de educação, as duas secretarias mantêm constante comunicação entre si.

Nas escolas de ensino fundamental, os diretores são eleitos por pais, alunos, conselho e demais profissionais de ensino (podem eleger até seis pessoas). Após a eleição, os eleitos fazem um curso e, caso sejam aprovados, ingressam num banco de nomes para o cargo de diretor e/ou diretor adjunto. Esse banco fica à disposição para que o diretor do centro de educação infantil, por exemplo, escolha seu adjunto. Os candidatos a diretor ou diretor adjunto devem ser profissionais efetivos da rede pública municipal.

No município C, nas unidades municipais de educação infantil não há diretores, mas vice-diretores. As unidades municipais de educação infantil não contam com diretor próprio; a direção da escola núcleo, à qual se vinculam responde, também pela direção dessas unidades. Ao serem criadas, essas unidades municipais definiram que o cargo de vice-diretor poderia ser exercido por servidores, entretanto, o município não estabelece cargo de diretor para as instituições.

O ingresso de diretores no município A ocorre por meio de eleições, organizadas pelo Departamento de Gestão Democrática; é necessária experiência mínima de dois anos como docente para o exercício da direção. A eleição é feita a cada quatro anos e o diretor pode ser reconduzido por mais um mandato consecutivo.

No município E, o cargo do diretor das instituições é comissionado. Apesar de ser selecionado por eleição, do ponto de vista legal, quem o nomeia é o prefeito municipal. O processo de eleição, regulamentado a cada dois anos por um decreto do poder executivo, ocorre por eleição direta, em que votam comunidade escolar, pais e alunos. A organização desse processo ocorre por intermédio da formação de uma comissão na secretaria e uma comissão na escola. Para candidatar-se ao cargo de diretor, o professor deve apresentar um projeto para a unidade educativa. Um auxiliar de ensino pode se candidatar também, desde que tenha a formação mínima requerida, que é licenciatura.

Cabe destacar que o candidato a diretor deve elaborar seu plano de gestão em consonância com o projeto pedagógico da instituição. Como afirmado na entrevista, o projeto pedagógico pertence à unidade e não ao diretor, o que significa que o este deverá executar seu plano articulado com a proposta da instituição. Parece interessante essa posição da secretaria, uma vez que salienta a importância do projeto pedagógico e dificulta o rompimento com o trabalho 
realizado pela gestão anterior.

\section{CONSIDERAÇÕES FINAIS}

Verificou-se, nas entrevistas realizadas nas Secretarias Municipais de seis capitais brasileiras que a supervisão das instituições diretas de educação infantil está fortemente vinculada a atividades de formação continuada, algumas vezes se confundindo com o trabalho de formação. São frequentes as pautas de supervisão organizadas em torno dos temas de formação. Ainda que a preocupação com a formação continuada seja importante, o foco da supervisão é, nesse caso, o repertório de conhecimentos do professor.

Um modelo organizacional que pareceu mais consistente dentre os municípios estudados foi aquele em que a atividade de supervisão estava estreitamente articulada ao projeto pedagógico das instituições. Nota-se que o projeto pedagógico orientava as pautas das visitas dos supervisores, no que se refere à proposta curricular das instituições, a formação continuada dos professores e as práticas educativas definidas no projeto. Estas, por sua vez, deveriam fundamentar-se em documentos e diretrizes municipais. Nesse caso, observa-se um conjunto articulado de procedimentos e ações que percorre todas as instâncias administrativas e pedagógicas até à unidade de educação infantil, buscando estabelecer, mediante a ação do supervisor pedagógico, relação e coerência entre as políticas e as práticas educativas.

Em relação à supervisão das conveniadas, notou-se a restrição a procedimentos administrativos e financeiros. Ainda que os municípios tivessem documentos orientadores para subsidiar o trabalho pedagógico das instituições e o trabalho de supervisão, parece que as redes conveniadas não contemplavam as diretrizes e orientações curriculares elaboradas para as redes diretas. As possíveis explicações para isso são ou falta de esforços no sentido de promover a formação dos profissionais das conveniadas e verificar a utilização desses documentos ou o fato de as conveniadas não serem obrigadas a seguir as diretrizes da Secretaria Municipal de Educação, por uma série de motivos: tipo de convênio estabelecido com as prefeituras, forma de contratação de seus funcionários, encargos trabalhistas e jornadas de trabalho, entre outros. Essa questão da orientação pedagógica das unidades conveniadas é aspecto que exigiria investigação mais sistemática e aprofundada sobre a supervisão das instituições conveniadas, uma vez que é uma importante e com reflexos sobre a qualidade da educação oferecida e sobre a política municipal implementada no tocante à educação infantil.

Com relação aos planos de carreira, um aspecto que chama a atenção é o fato de existirem planos distintos para professores e auxiliares de ensino, o que acarreta, dentre outros aspectos, a exigência de formações mínimas diferenciadas: 
enquanto do professor exige-se ensino superior, do auxiliar, é exigido ensino médio, na modalidade normal. No entanto, a jornada de trabalho dos auxiliares é maior e os salários, inferiores ao do professor.

Há também o caso do município $\mathrm{C}$, em que o professor de Educação Infantil, denominado educador infantil, possui plano de carreira distinto do plano dos demais professores da educação básica. Essa situação contribui para acentuar as desigualdades entre os profissionais das diferentes etapas da educação básica e reforça alguns fatores que prejudicam a qualidade de atendimento em educação infantil, como a formação mais precária dos auxiliares, a falta de programas de formação continuada para os auxiliares e a diferença salarial entre as categorias.

Por fim, verifica-se que o concurso público não é procedimento utilizado no provimento do cargo de diretor de unidade de educação infantil, sendo mais comum a indicação, seguida da eleição. Percebeu-se que a indicação é uma forma de provimento que tem as suas raízes nas secretarias de assistência social e que alguns municípios têm tentado mudar esse cenário. No entanto, há dúvidas sobre se a eleição é o melhor procedimento para a ocupação do cargo de direção, na medida em que parece ter acentuado posturas clientelistas e disputas internas no ensino fundamental, como reconhecido por uma das entrevistadas.

Como constataram Kramer e Nunes (2007) em seu estudo sobre a educação infantil em municípios do Rio de Janeiro, a descontinuidade e as práticas de interferência política nos sistemas municipais são fatores que comprometem a busca de um maior profissionalismo na gestão das unidades. Um aspecto importante a ser investigado por outras pesquisas seria qual o papel que a escolha do diretor por eleição tem desempenhado na gestão das unidades, no contexto da educação infantil.

\section{REFERÊNCIAS}

CAMPOS, M. M. et al. A Gestão da Educação no Brasil. (Relatório de Pesquisa). São Paulo: Fundação Carlos Chagas, 2012.

CÔCO, V. Gestão na Educação Infantil: os processos de escolha dos dirigentes das instituições. XXIV Simpósio Brasileiro e III Congresso Interamericano de Política e Administração da Educação, 2009, Vitória, ES. Direitos Humanos e Cidadania: Programa e Trabalhos Completos. Niterói, RJ: ANPAE, 2009. p. 1-18.

KRAMER, S.; NUNES, M.F.Gestãopública, formação eidentidadedeprofissionais de educação infantil. Cadernos de Pesquisa, v. 37, n. , p. 423-454, mai./ago. 2007.

MOSS, P. Qual o futuro da relação entre educação infantil e ensino 
obrigatório? Cadernos de Pesquisa, v. 41, n. 142, p. 142-159, jan./abr., 2011.

\section{PINTO, Mércia F. N. O trabalho docente na educação infantil pública} em Belo Horizonte. 2009. 192 f. Dissertação (Mestrado em Educação) - Universidade Federal de Minas Gerais, UFMG, Belo Horizonte, 2009.

TOMÉ, M. F. A educação infantil foi para a escola, e agora? Ensaio de uma teoria para a gestão institucional da educação infantil. 2011, 298 f. Tese (Doutorado em Educação) - Universidade Estadual Júlio de Mesquita Filho, Marília-SP, 2011.

FABIANA SILVA FERNANDES possui graduação em Pedagogia pela Universidade Estadual Paulista Júlio de Mesquita Filho (1999) e doutorado em Educação Escolar pela Universidade Estadual Paulista Júlio de Mesquita Filho (2006). Foi professora da Pontífícia Universidade Católica, de Campinas e, atualmente, é pesquisadora da Fundação Carlos Chagas. Possui experiência em Educação, atuando nas seguintes áreas: política educacional, planejamento e gestão educacional e educação infantil.e-mail: fsfernandes@fcc.org.br

MARIA MALTA CAMPOS possui graduação em Pedagogia pela Pontifícia Universidade Católica de São Paulo (1961) e doutorado em Ciências Sociais pela Universidade de São Paulo (1982). Realizou estágios de pós-doutorado na Universidade de Stanford e na Universidade de Londres. É professora do Programa de Pós-graduação em Educação - Currículo da Pontifícia Universidade Católica de São Paulo, presidente da diretoria colegiada da ONG - Ação Educativa e pesquisadora da Fundação Carlos Chagas. Foi presidente da Associação Nacional de Pós-graduação e Pesquisa em Educação (ANPEd). Tem experiência na área de Educação, atuando principalmente nos seguintes temas: educação infantil, creche, qualidade da educação e política educacional. e-mail: mcampos@fcc.org.br

Recebido em julho de 2014

Aprovado em fevereiro de 2015 